\title{
Global warming accelerates uptake of atmospheric mercury in regions experiencing glacier retreat
}

\author{
XUN WANG ${ }^{1}$, Wei YUAN ${ }^{2}$, CHE-JEN LiN ${ }^{3}$, FEIYUE \\ WANG $^{4}$, XINBIN FENG $^{5}$ \\ ${ }^{1}$ College of Resources and Environment, Southwest \\ University, China; xunwang@swu.edu.cn \\ ${ }^{2}$ State Key Laboratory of Environmental Geochemistry, \\ Institute of Geochemistry, Chinese Academy of Sciences, \\ Guiyang, China; yuanwei@mail.gyig.ac.cn \\ ${ }^{3}$ Center for Advances in Water and Air Quality, Lamar \\ University, USA; lincx@lamar.edu \\ ${ }^{4}$ Centre for Earth Observation Science, and Department of \\ Environment and Geography, University of Manitoba, \\ Winnipeg, Manitoba, Canada;feiyue.wang@umanitoba.ca \\ ${ }^{5}$ State Key Laboratory of Environmental Geochemistry, \\ Institute of Geochemistry, Chinese Academy of Sciences, \\ Guiyang, China; fengxinbin@vip.skleg.cn
}

As global climate continues to warm, melting of glaciers releases a large quantity of mercury $(\mathrm{Hg})$ originally locked in ice into the atmosphere and downstream ecosystems. Here we show an opposite process that captures atmospheric $\mathrm{Hg}$ through glacier-to-vegetation succession. Our study using stable isotope techniques at three succession sites on the Tibetan Plateau reveals that evolving vegetation serves as an active "pump" to take up gaseous elemental mercury $\left(\mathrm{Hg}^{0}\right)$ from the atmosphere. The accelerated uptake enriches the $\mathrm{Hg}$ pool size in glacier retreated areas by a factor of $\sim 10$ compared to the original pool size in the glacier. Through an assessment of $\mathrm{Hg}$ source-sink relationship observed in documented glacier retreated areas in the world (seven sites of tundra/steppe succession and five sites of forest succession), we estimate that $400-600 \mathrm{Mg}$ of $\mathrm{Hg}$ have been accumulated in glacier retreated areas $(5 \%$ of the global land surface) since the Little Ice Age ( 1850). By 2100, an additional $\sim 300 \mathrm{Mg}$ of $\mathrm{Hg}$ will be sequestered from the atmosphere in glacier retreated regions globally, which $\sim 3$ times the total $\mathrm{Hg}$ mass loss by meltwater efflux $(\sim 95 \mathrm{Mg})$ in alpine and subpolar glacier regions. The recapturing of atmospheric $\mathrm{Hg}$ by vegetation in glacier retreated areas is not accounted for in current global $\mathrm{Hg}$ models. Similar processes are likely to occur in other regions that experience increased vegetation due to climate or land-use changes, which need to be considered when assessing global $\mathrm{Hg}$ cycling. 